\title{
Topographic characterization of canine teeth using atomic force microscopy images in nano-scale
}

\author{
Negin Beryani Nezafat ${ }^{1} \cdot$ Mahmood Ghoranneviss $^{1}$ - Seyed Mohammad Elahi ${ }^{1}$ - Azizollah Shafiekhani ${ }^{2,3}$. \\ Zohreh Ghorannevis ${ }^{4}$. Shahram Solaymani ${ }^{1,3}$
}

Received: 9 July 2019 / Accepted: 21 October 2019 / Published online: 1 November 2019

(C) The Author(s) 2019

\begin{abstract}
The purpose of the present study was to investigate a new method to evaluate micro topography and micro morphology of hard tissue of canine teeth using an atomic force microscope (AFM). For this aim, three extracted human canine teeth were applied. The unpolished surfaces were analyzed with AFM images with $15 \mu \mathrm{m} \times 5 \mu \mathrm{m}$ area and their information obtained by power spectral density (PSD) method and fast Fourier transform algorithm. It was observed that PSD analyses extract suitable information about surface morphological variations so that by moving from enamel to cementum, the fractal dimension and surface complexity were increased.
\end{abstract}

Keywords Canine tooth $\cdot$ Surface morphology $\cdot$ Power spectral density

\section{Introduction}

Surface morphology at nanoscale is a key factor in technological applications as well as fundamental science [1-3]. In the past decade, atomic force microscope (AFM) images were considered as the best source of information about surface topography obtained through a very small probe which forms the profile of the surface morphology quantitatively [4]. There exist various types of methods which give information about surface texture, i.e. surface regulations including skewness, power spectral density (PSD), autocorrelation function, RMS roughness, and fractal dimension (Df) [5]. Statistical descriptions of RMS roughness represent the average square of the difference between the heights of peaks and valleys and they do not describe lateral distribution. One of the significant differences between investigating

Seyed Mohammad Elahi

smohammad_elahi@srbiau.ac.ir

1 Department of Physics, Faculty of Sciences, Science and Research Branch, Islamic Azad University, Tehran, Iran

2 Physics Department, Alzahra University, Tehran 1993891167, Iran

3 School of Physics, Institute for Research in Fundamental Sciences (IPM), P.O. Box 19395-5531, Tehran, Iran

4 Department of Physics, Karaj Branch, Islamic Azad University, Karaj, Iran surface topography by RMS roughness and PSD methods is that the first method does not describe surfaces with complex morphology and behavior in the appropriate way since it may show the same value of RMS roughness. In addition, the first method depends just on the length scale. Thus, PSD is a more accurate method due to its ability in performing fast Fourier transform (FFT) of the squared height profile versus wavelength. PSD method helps to compare roughness in different spatial frequency regions $[6,7]$.

Among various types of surfaces whose morphology can be estimated, human tooth attracts a lot of attention nowadays [8]. Enamel, dentin, and cementum are three hard tissues which form human tooth. Amongst, enamel which covers the crown is the most rigid and mineralized tissue whose main content is $96 \mathrm{wt} \%$ inorganic materials mainly composed of hydroxyapatite (HAP) crystals [9] composed of phosphorous and calcium. Formation of enamel, called amelogenesis, occurs by cytodifferentiation, matrix secretion, and maturation process [10]. Dentin is the second tissue which contains dental pulps and it is composed of mineral components and complex protein [11]. Dentin is formed by odontoblasts where $30 \%$ and $50 \%$ of its compositions are collagen and HAP minerals [12]. Finally, Cementum, whose composition is similar to bone, is mainly composed of HAP (65 wt \%), along with organic matrix including collagen and noncollagenous proteins and also water [13]. These tissues with their complex structure are highly organized. In order to investigate surface morphology 
of enamel, dentin, and cementum, atomic force microscopy (AFM) was applied as the best technique to specify surface morphology along $x, y$, and $z$ axes. The aim of the present work was to analyze AFM images of hard tissue of canine teeth by PSD plots which provide information about height distribution. Afterward, fractal geometry was extracted through FFT algorithm as a tool which can describe dental complex nature. The calculated parameters can affect physical properties of each tissue as the hallmark of fractals.

\section{Experimental details}

In a dental clinic, three extracted human canine teeth were placed in saline and transferred to the laboratory. After when they reached the laboratory, they were all cleaned ultrasonically and finally air-dried. Each tooth was sectioned with diamond discs (Discoflex, KG Sorensen, Brazil) to access inter enamel. Enamel, inter enamel, dentin, and cementum tissue of each tooth were imaged with an AFM (Veeco, Santa Barbara, CA, USA) in non-contact mode at room temperature with scan rates of $10-20 \mu \mathrm{m} / \mathrm{s}$ over square areas of $1 \mu \mathrm{m} \times 1 \mu \mathrm{m}$. Quantitative information including PSD and fractal dimension was obtained from the AFM images.

\section{Results and discussion}

\section{Morphological analysis}

As mentioned before, Rrms evaluation does not give essential information about height scale and makes scientists replace it with another statistical parameter called PSD which describes roughness changes with length scale.

PSD is defined as the square of surface roughness amplitude versus wavelength which is applied to compare surface quality quantitatively [14]. AFM images are for PSD analysis as presented in Fig. 2 for all tissue. Figure 3 represents the PSD plots of dental hard tissue, i.e. enamel out, inter enamel, dentin, and cementum calculated through FFT algorithm. Moreover, frequency distribution versus frequency are calculated by FFT and finally PSD functions as $|F(x, y)|^{2}$ in which $F(x, y)$ are FFT coefficients. On the other hand, normalizing PSD reaches units of (length) ${ }^{4}[15]$.

Microstructure fractal information is obtained by PSD versus spatial frequency [16] via AFM data. The following equation describes PSD function [17]:

$S_{2}\left(f_{x}, f_{y}\right)=\left[\frac{1}{L^{2}}\left[\sum_{m=1}^{N} \sum_{n=1}^{N} Z_{m n} \mathrm{e}^{-\mathrm{e} \pi i \Delta L\left(f_{x} m+f_{y} n\right)}(\Delta L)^{2}\right] \frac{1}{L^{2}}\right.$,

where $S_{2}$ denotes 2D PSD and $N$ and $L^{2}$ are data points and surface area. $N=181$ in the present study. $f_{x}$ and $f_{y}$ are the spatial frequency and $\Delta L=L / N$ [18]. Also, PSD in polar coordinates and frequency space is obtained through

$S_{2}(f)=\frac{1}{2 \pi} \int_{1}^{2 \pi} S_{2}(f, \varphi) \mathrm{d} \varphi$.

We have

$\operatorname{PSD}(f)=\frac{K}{f^{-\gamma}}$.

In addition, the power $\gamma$ is the inverse slope of $\log -\log$ plot of PSD-K. Here, sample rate is $30.12 \mu \mathrm{m}^{-1}$ while $L$ is set as $3.0 \mu \mathrm{m}$ [19]. On the other hand, the relationship between $S(k)$ which is defined as PSD and $K$ is illustrated in Eq. (5) while the slope of a $\log S(k)-\log k$ plot ends at Df [20]:

$S(k) \propto k^{-\beta}$.

Moreover, the relation between Df and the slope of $\log -\log$ plot is given by $\beta$ in Eq. (6), which is presented by as follows:

$D=4+\beta / 2$.

At different scales, $D$ determines surface irregularities (Fig. 1).

From another aspect, $\mathrm{PSD}_{A B C}$ plots can be described by $k$-correlation function which gives information about plot features [20] and hence, by considering $f$ as the spatial frequency, it is defined as follow:

$\operatorname{PSD}_{A B C}=\frac{A}{\left(1+B^{2} f^{2}\right)^{\frac{(C+1)}{2}}}$.

Here, " $A$ " is the magnitude of low spatial frequency, " $B$ " is the 'knee,' i.e. the slope of connective line between two points of the surface of enamel, dentin, and camentum, and " $C$ " with its constant value refers to the nature of roughness.

In Fig. 2, high spatial frequency region is characterized. While the shapes of curves were similar in both low- and mid-frequency region where the most energy exists, some differences were observed in the specified region. As mentioned before, tooth structures in all tissue are fine and highly organized and they increase by increasing fractal dimension $(D)$. The results of Fig. 1 are summarized in Table 1 and it was observed that decreasing slope ends increase of fractal dimension at high-frequency region which occurs by moving from enamel to dentin and cementum.

In Fig. 3, the slope variation $(D)$ of $\log$ PSD- $\log K$ diagram was estimated for enamel and confirms the dependency of $D$ to frequency and spectrum region. In addition, the results of Fig. 3 are presented in Table 2. As can be seen, the best fitted line in Fig. 3 is line III since slope changes depend directly on spectral range, frequency, and data size 


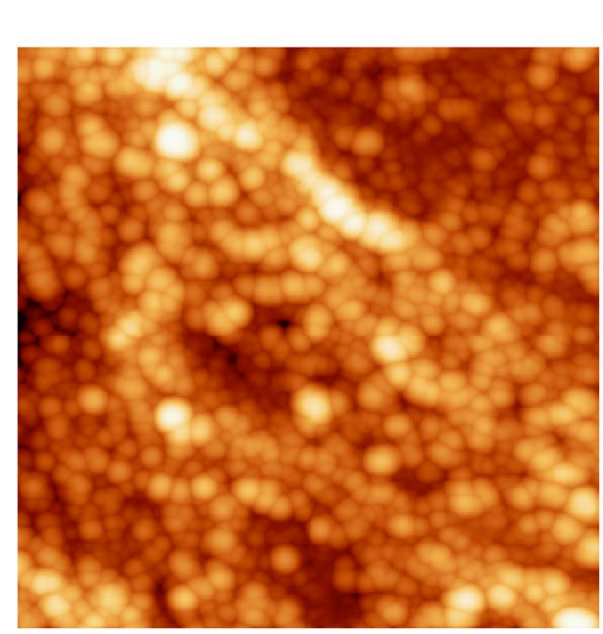

(a)

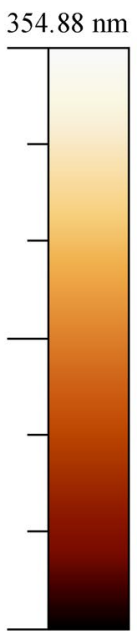

$0.00 \mathrm{~nm}$

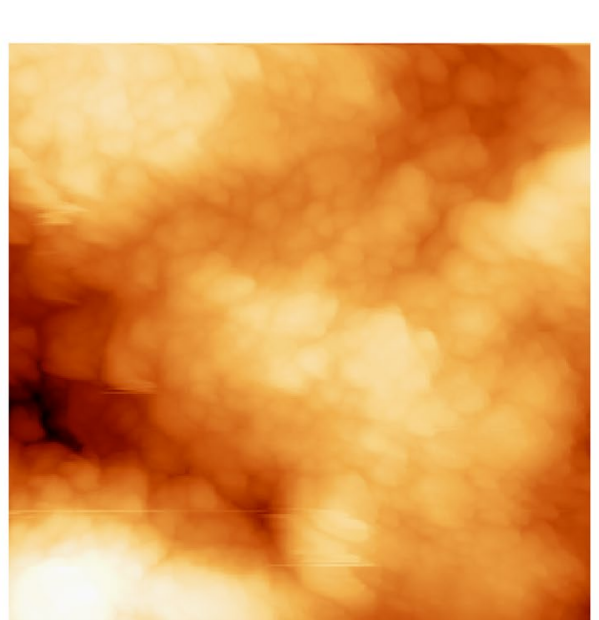

(b)

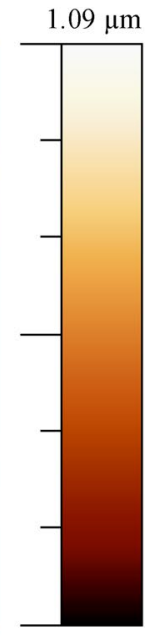

$0.00 \mu \mathrm{m}$

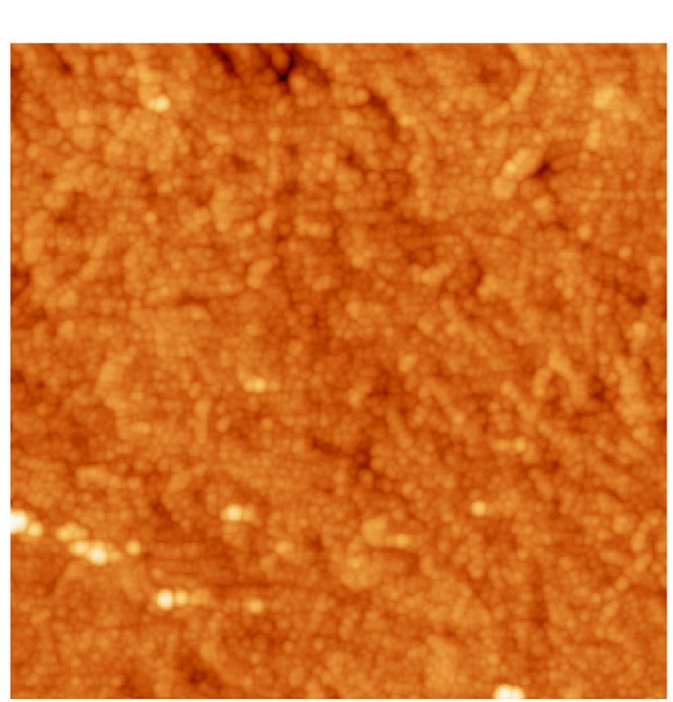

(c)

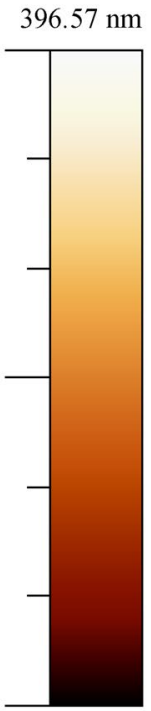

$0.00 \mathrm{~nm}$

Fig. 1 AFM images $\left(1 \times 1 \mu \mathrm{m}^{2}, 512 \times 512\right.$ pts $)$ of each dental tissue: a enamel, $\mathbf{b}$ dentin, $\mathbf{c}$ cementum

[20]. Moreover, Tables 3 and 4 describe the dependency of slope and fractal dimension on dentin and cementum. Hence, in enamel, increase of fractal dimension takes place by decreasing slope.

Moreover, Table 3 shows that by decreasing slope from low to mid frequency region in dentin, fractal dimension was increased while by moving to high-frequency region, increasing slope reduces the fractal dimension. In Table 4, as can be seen for cementum, increasing frequency from low to mid decreases fractal dimension while moving from mid to high-frequency region decreases the slope which finally ends in increase of fractal dimension.

According to Raman spectra of enamel and cementum in Fig. 4, a large variety of lines are due to mechanical stress whose width confirms their solid nature with a complex structure. Moreover, strong peak at $960 \mathrm{~cm}^{-1}$ represents HAP structure (PO4 functional group) which is similar in both tissue but with more intensity in enamel. As can be seen, the mentioned peak is surrounded by weak peaks around it. Wide bands are also observed in cementum in the range of $900 \mathrm{~cm}^{-1}$ to $1100 \mathrm{~cm}^{-1}$. There are some similarities in phosphate bands of enamel and cementum. On the other hand, the groups of amides and organic materials are revealed at 1450 , and $1245 \mathrm{~cm}^{-1}$ while double $\mathrm{C}-\mathrm{O}$ bond is illustrated in the range $1600-1700 \mathrm{~cm}^{-1}$. 


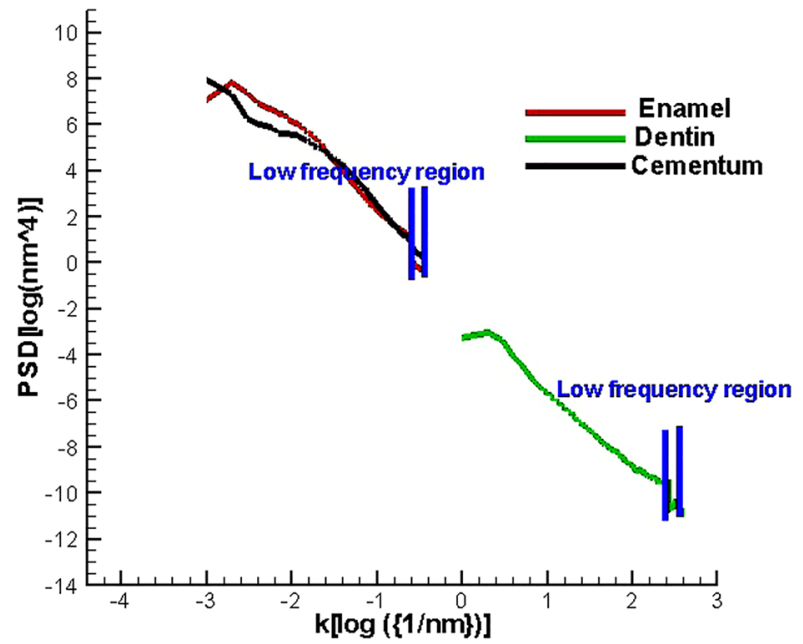

Fig. 2 The spectral log PSD-log $K$ plots for each dental tissue and their comparison

Table 1 The values of Df for each tissue extracted from Eq. (6)

\begin{tabular}{lll}
\hline Sample & Slope & $\begin{array}{l}\text { Fractal } \\
\text { dimension } \\
(D)\end{array}$ \\
\hline Enamel & -3.420 & 2.29 \\
Dentin & -3.158 & 2.42 \\
Cementum & -2.517 & 2.70 \\
\hline
\end{tabular}

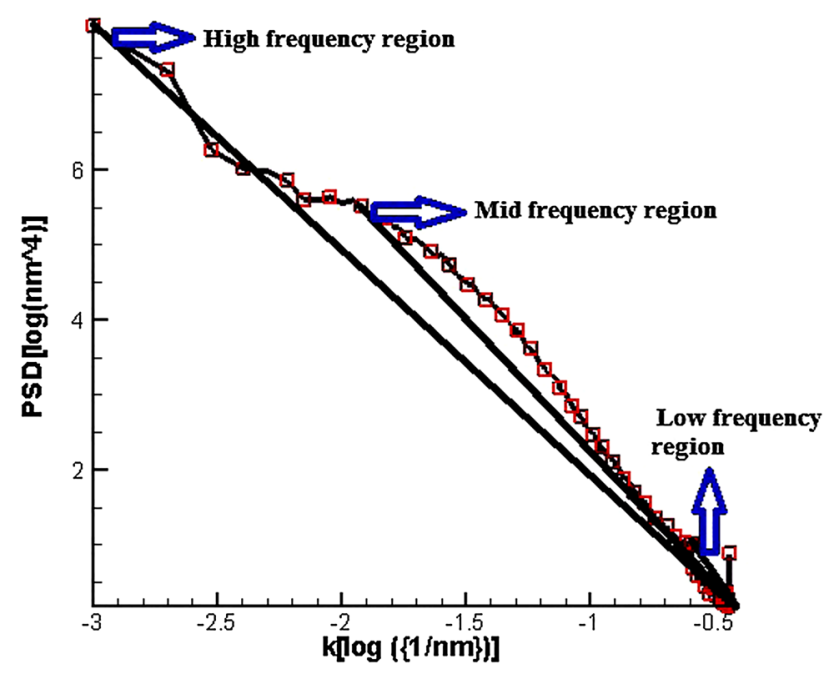

Fig. 3 The diagram of log PSD-log frequency which confirms the effect of frequency region on the values of slopes in enamel

\section{Conclusion}

Table 2 The values of Df and slopes in specified frequency region of enamel

\begin{tabular}{lll}
\hline $\begin{array}{l}\text { Frequency } \\
\text { region }\end{array}$ & Slope & Df \\
\hline Low & -4.006 & 1.99 \\
Mid & -3.826 & 2.08 \\
High & -3.158 & 2.42 \\
\hline
\end{tabular}

Table 3 The values of Df and slopes in specified frequency region of dentin

\begin{tabular}{lll}
\hline $\begin{array}{l}\text { Frequency } \\
\text { region }\end{array}$ & Slope & Df \\
\hline Low & -3.153 & 2.42 \\
Mid & -3.132 & 2.43 \\
High & -3.607 & 2.20 \\
\hline
\end{tabular}

Table 4 The values of Df and slopes in specified frequency region of cementum

\begin{tabular}{lll}
\hline $\begin{array}{l}\text { Frequency } \\
\text { region }\end{array}$ & Slope & Df \\
\hline Low & -3.612 & 2.19 \\
Mid & -4.005 & 1.99 \\
High & -2.517 & 2.70 \\
\hline
\end{tabular}

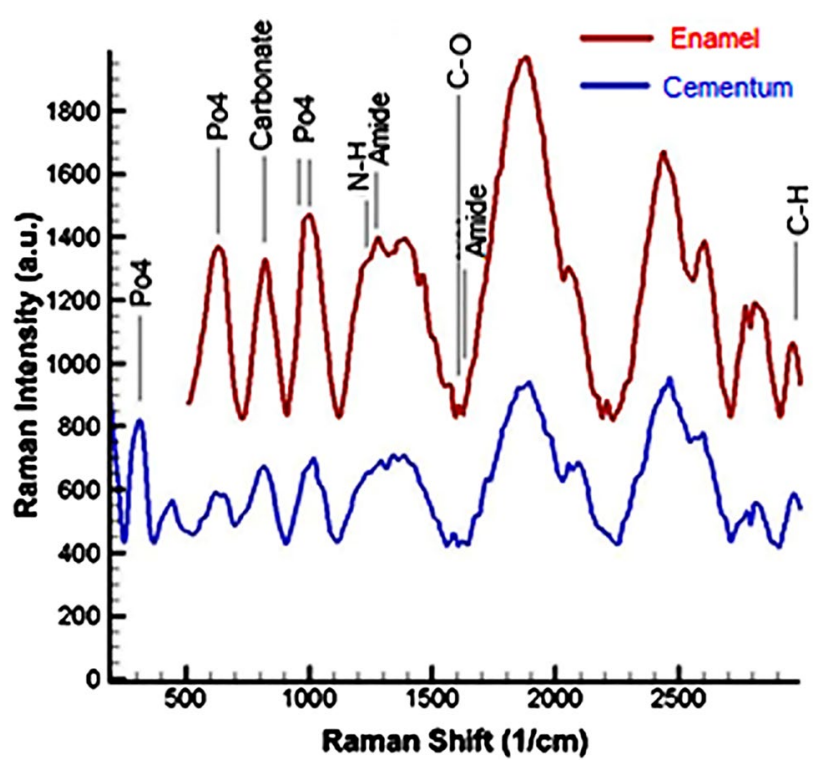

Fig. 4 Raman spectra of cementum (top) and enamel (bottom)

The present work focused on the surface morphology of hard tissue of canine tooth including enamel, dentin, and cementum. The obtained results confirm that PSD method and fractal dimension are the best candidates for measuring surface morphology and performing functional characteristics of surface. According to the statistical parameters obtained from 3D AFM images, surface roughness parameters were measured precisely so that 
surface characterization was strongly affected by external factors. In addition, the dependency of surface roughness on the slope of $\log$ PSD- $\log K$ diagram along with fractal dimensions was investigated for different dental tissue. As can be seen, increasing slope ends in increase of fractal dimension and surface complexity. Moreover, by moving from enamel to cementum, fractal dimension has been increased. Finally, fine but complex structure of dental tissues was observed through Raman spectra in which functional groups of HAP were clear.

\section{Compliance with ethical standards}

Conflict of interest The authors report no conflict of interests. The authors alone are responsible for the content and writing of the paper.

Open Access This article is distributed under the terms of the Creative Commons Attribution 4.0 International License (http://creativeco mmons.org/licenses/by/4.0/), which permits unrestricted use, distribution, and reproduction in any medium, provided you give appropriate credit to the original author(s) and the source, provide a link to the Creative Commons license, and indicate if changes were made.

\section{References}

1. Mahmoodi, A., Solaymani, S., Amini, M., Nezafat, N.B., Ghoranneviss, M.: Structural, morphological and antibacterial characterization of CuO nanowires. Silicon 10(4), 1427-1431 (2018). https ://doi.org/10.1007/s12633-017-9621-2

2. Dejam, L., Solaymani, S., Achour, A., Stach, S., Ţălu, Ş., Nezafat, N.B., Dalouji, V., Shokri, A., Ghaderi, A.: Correlation between surface topography, optical band gaps and crystalline properties of engineered AZO and CAZO thin films. Chem. Phys. Lett. 719, 78-90 (2019). https://doi.org/10.1016/j.cplett.2019.01.042

3. Solaymani, S., Kulesza, S., Ţălu, Ş., Bramowicz, M., Nezafat, N.B., Dalouji, V., Rezaee, S., Karami, H., Malekzadeh, M., Dorbidi, E.S.: The effect of different laser irradiation on geometric and micro topographic features in zirconia ceramics: Study of surface statistical metrics. J. Alloys Compd. 765, 180-185 (2018). https://doi.org/10.1016/j.jallcom.2018.06.213

4. Ţălu, Ş., Yadav, R.P., Lainovic, T., Méndez-Albores, A., Trejo, G., Kukuruzovic, D., Nezafat, N.B., Shafiekhani, A., Solaymani, S.: The effect of dental LED light-curing unit photoactivation mode on 3D surface morphology of dental nanocomposites evaluated by two-dimensional multifractal detrended fluctuation analysis. Microsc. Res. Tech. 81(10), 1223-1230 (2018). https://doi. org/10.1002/jemt.23123

5. Ţălu, Ş., Bramowicz, M., Kulesza, S., Solaymani, S.: Topographic characterization of thin film field-effect transistors of 2,6-diphenyl anthracene (DPA) by fractal and AFM analysis. Mater. Sci. Semicond. Process. 79, 144-152 (2018). https://doi.org/10.1016/j. mssp.2018.02.008

6. Gavrila, R., Dinescu, A., Mardare, D.: A power spectral density study of thin films morphology based on AFM profiling. Rom. J. Inf. Sci. Technol. 10, 291-300 (2007)

7. Solaymani, S., Elahi, S.M., Nezafat, N.B., Zahrabi, H., Boochani, A., Naseri, M.: Characterization of microroughness parameters in
$\mathrm{Cu}-\mathrm{C}$ nanocomposite prepared by co-deposition of RF-sputtering and RF-PECVD. Eur. Phys. J. Appl. Phys. 64(1), 11301 (2013). https://doi.org/10.1051/epjap/2013130121

8. Nezafat, N.B., Ghoranneviss, M., Elahi, S.M., Shafiekhani, A., Ghorannevis, Z., Solaymani, S.: Microstructure, micromorphology, and fractal geometry of hard dental tissues: evaluation of atomic force microscopy images. Microsc. Res. Tech. (2019). https://doi.org/10.1002/jemt.23356

9. Nanci, A.: Ten Cate's Oral Histology: Development, Structure and Function. Mosby, St. Louis Missouri (2007)

10. Kahler, B., Swain, M.V., Moule, A.: Fracture-toughening mechanisms responsible for differences in work to fracture of hydrated and dehydrated dentine. J. Biomech. 36(2), 229-237 (2003)

11. Bertassoni, L.E., Orgel, J.P., Antipova, O., Swain, M.V.: The dentin organic matrix-limitations of restorative dentistry hidden on the nanometer scale. Acta Biomater. 8(7), 2419 (2012). https:// doi.org/10.1016/j.actbio.2012.02.022

12. Goldberg, M., Takagi, M.: Dentine proteoglycans: composition, ultrastructure and functions. J. Mol. Histol. 25(11), 781-806 (1993). https://doi.org/10.1007/bf00188045

13. Solaymani, S., Ghoranneviss, M., Elahi, S.M., Shafiekhani, A., Kulesza, S., Ţălu, Ş., Bramowicz, M., Hantehzadeh, M., Nezafat, N.B.: The relation between structural, rugometric and fractal characteristics of hard dental tissues at micro and nano levels. Microsc. Res. Tech. 82(4), 421-428 (2018). https://doi. org/10.1002/jemt.23183

14. Kubiak, K.J., Bigerelle, M., Mathia, T.G., Dubois, A., Dubar, L.: Dynamic evolution of interface roughness during friction and wear processes. Scanning 36, 30-38 (2014). https://doi. org/10.1002/sca.21082

15. Jiang, T., Hall, N., Ho, A., Morin, S.: Quantitative analysis of electrodeposited tin film morphologies by atomic force microscopy. Thin Solid Films 471, 76-85 (2005). https://doi.org/10.1016/j. tsf.2004.04.051

16. Sahoo, N.K., Thakur, S., Senthilkumar, M., Bhattacharyya, D., Das, N.C.: Reactive electron beam evaporation of gadolinium oxide optical thin films for ultraviolet and deep ultraviolet laser wavelengths. Thin Solid Films 440, 155-168 (2003). https://doi. org/10.1016/s0040-6090(03)00678-3

17. Ferre-Borrull, J., Duparre, A., Quesnel, E.: Procedure to characterize microroughness of optical thin films: application to ion-beam-sputtered vacuum-ultraviolet coatings. Appl. Opt. 40, 2190-2199 (2001). https://doi.org/10.1364/ao.40.002190

18. Martínez, J.F.G., Carvajal, I.N., Abad, J., Colchero, J.: Nanoscale measurement of the power spectral density of surface roughness: how to solve a difficult experimental challenge. Nanoscale Res. Lett. 7(1), 174 (2012). https://doi.org/10.1186/1556-276x-7-174

19. Jakops, S., Duparre, A., Truckenbrodt, H.: Interfacial roughness and related scatter in ultraviolet optical coatings: a systematic experimental approach. Appl. Opt. 37, 1180-1193 (1998). https ://doi.org/10.1364/ao.37.001180

20. Solaymani, S., Ghaderi, A., Nezafat, N.B.: Comment on: characterization of microroughness parameters in titanium nitride thin films grown by DC magnetron sputtering. J. Fusion Energy 31, 591 (2012). https://doi.org/10.1007/s10894-012-9510-z

Publisher's Note Springer Nature remains neutral with regard to jurisdictional claims in published maps and institutional affiliations. 